\section{Summer reading}

While summer reading traditionally brings to mind the latest pulp-fiction fare, this year's Summer Reading section in The Left Atrium aims to provide something for every palate, from a Dr. Seuss-esque take on disease mongering to the history of Canadian hospital architecture, from poetical musings to physician wellness. Enjoy.

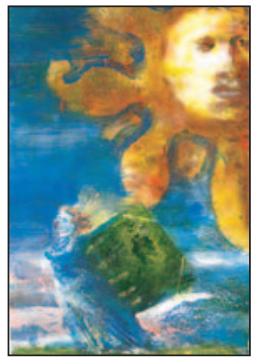

\section{Honouring the dead}

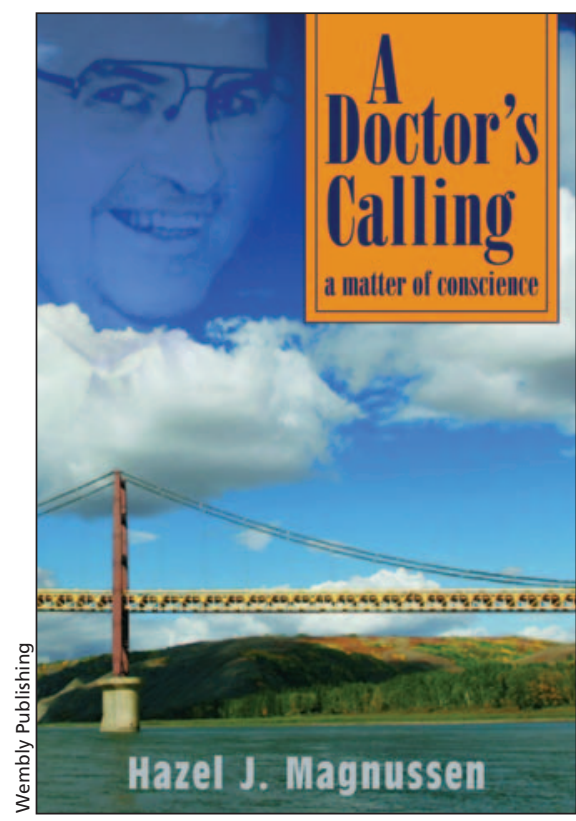

A Doctor's Calling: a matter of conscience Hazel J. Magnussen RN BSCN Wembley Publishing: 2006 182 pp \$26.95 ISBN 0-9739843-0-9

$\mathrm{M}$ edicine has taken to heart the need to take care of its own. Most Canadian medical schools now offer a physician health curriculum at the under- and postgraduate level, and residents frequently have sessions on aspects of their wellness and sustainability. Physician health programs, once synonymous with addiction and mental illness, are increasingly doing more in the realm of health promotion and disease prevention. Perhaps of most relevance, they are also being increasingly called upon to help identify, manage, and monitor physicians with disruptive behaviour.

As a construct, disruptive behaviour first appeared in the literature in the last century ${ }^{1}$ but has only recently become an issue of urgent public policy. ${ }^{2}$ In 2008, the College of Physicians and Surgeons of Ontario released a policy paper describing disruptive behaviour as having occurred: “... when the use of inappropriate words, actions or inactions by a physician interferes with his or her ability to function well with others to the extent that the behaviour interferes with, or is likely to interfere with, quality health care delivery."

Disruptive behaviour is associated with multiple and serious outcomes, including nursing shortages, ${ }^{4}$ patient safety and quality of care, para-medical professional sustainability and peer retention. ${ }^{5}$ Across Canada, disruptive behaviour has also been associated with tragic patient, peer and personal outcomes including, but not limited to, murder, suicide and neglect.

The community of Fairview, Alberta, knows these outcomes far too well. For several years, Dr. Doug Snider had been involved in managing a growing number of complaints about a colleague's professional behaviour from patients, health professionals, colleagues and administrators. After an in- ternal investigation, the local hospital removed the admitting privileges of Dr. Abe Cooper, who appealed that decision for several years. Two months after losing his appeal, he invited Snider to have a private conversation at his office. That evening, a series of disturbing events occurred. First, Snider wrote a "confession" that specified he was part of a conspiracy to destroy Cooper's reputation and practice. Second, aside from large amounts of Snider's hair and blood in Cooper's office and car, Snider disappeared. Finally, Cooper left the country to attend a medical conference and returned shortly thereafter to not only deny any involvement in harm, but to also accuse Snider of staging his own disappearance so as to frame Cooper for murder. In 2000, Cooper was convicted by a jury of the manslaughter of Snider and was sentenced to more than 7 years in jail. This year, Cooper will be released from prison. Snider's body has yet to be found.

Hazel Magnussen's detailed and frank book, A Doctor's Calling: a matter of conscience, succinctly alerts readers to the difficult challenges associated with identifying and managing disruptive behaviour among physicians (www.doctorscalling.ca). She also shares her family's painful lessons about the Canadian justice system, and the key strategies they feel governments ought to enact to fully honour her brother's death. Well written and enriched with family photographs and personal 
anecdotes, Magnussen carefully reveals the often secret struggle faced by those tasked with managing disruptive behaviour. She also eloquently emphasizes the need for health systems and health leaders to develop expertise in preventing, identifying, and managing disruptive behaviour: "The time has come for the medical community to take stock of its responses to reports of difficult behaviour on the part of physicians. It is time to adopt a zero tolerance approach to abusive and disruptive behaviour. Surely, the matter deserves the same kind of attention as is given to substance abuse" (page 160).

Magnussen also questions the privilege of self-regulation held by the profession, noting that most physician colleges have yet to develop a transparent, rigorous and appropriate model to prevent or address disruptive behaviour. Her message is crystal clear: self regulation and the criminal justice system both failed her brother, his family, and the community he served. We can, and ought to, do better.

In medicine, we are trained to honour death, particularly when the death is in error or preventable. Magnussen's book challenges us to improve our accepted standards of behaviour, clarify and make transparent our pathways for evaluating and managing disruptive behaviour, and strive to ensure no further harm is done by bullies or systems unwilling to rehabilitate or remove them. Snider's death deserves no less an honour.

\section{Derek Puddester MD}

Director, Faculty Wellness Program University of Ottawa

Ottawa, Ont.

\section{REFERENCES}

1. Piper LE. Addressing the phenomenon of disruptive physician behaviour. Health Care Manag (Frederick) 2003;22:335-9.

2. Pfifferling JH. Managing the unmanageable: the disruptive physician. Fam Pract Manag 1997;4:76-92.

3. College of Physicians and Surgeons of Ontario. Physician behaviour in the professional environment. Toronto: The College: 2008. Available: www.cpso.on.ca/policies/behaviour.htm (accessed 2008 May 28).

4. Rosenstein AH, Russell H, Lauve R. Disruptive physician behaviour contributes to nursing shortage. Physician Exec 2002;28:8-11.

5. Barnsteiner JH, Madigan C, Spray TL. Instituting a disruptive conduct policy for medical staff. $A A C N$ Clin Issues 2001;12:378-82.

\section{Skeptic's delight}

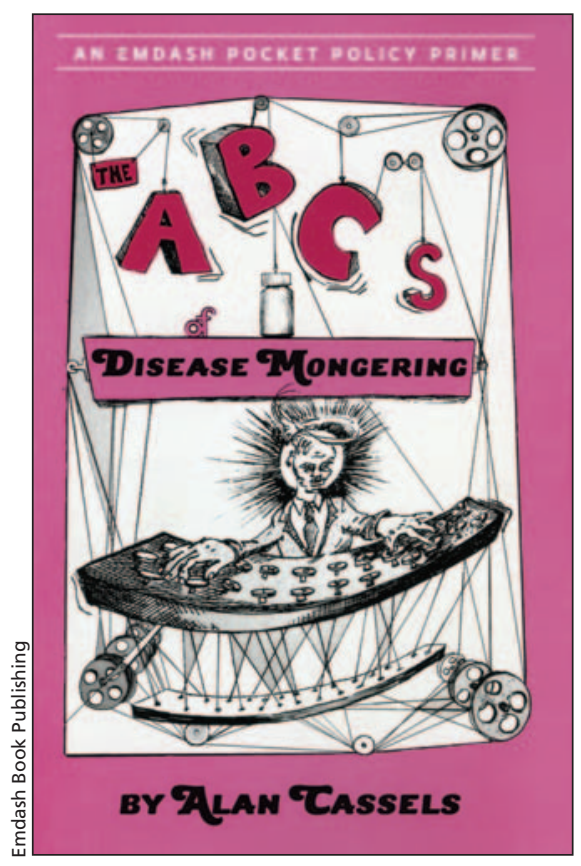

The ABCs of Disease Mongering:

An Epidemic in $\mathbf{2 6}$ Letters

Alan Cassels

Emdash Book Publishing; 2007

116 pp \$9.95 ISBN 978-0-9780182-3-8

\section{$\mathrm{T}$} he Greek philosopher Zeno once convincingly proved that motion is impossible. Where, he inquired, does it occur? Does it occur where it is? Obviously not, because there would not then have been any manner of motion. Does it, then, occur where it is not? Well, what could possibly occur where it is not?

Ergo, motion is impossible.

It's difficult not to be reminded of Zeno's dialectic arguments while reading medical skeptic Alan Cassels' new book, The ABCs of Disease Mongering: An Epidemic in 26 Letters, if only because it all but induces a state of paralysis.

The University of Victoria pharmaceutical policy researcher uses clever tools - children's verse, one for each letter of the alphabet - to illustrate a ceno tral proposition: that the only legitimate response to many aspects of, and practices within, modern pharmaceuticalbased medicine is a generous dollop of skepticism.

Many interventions, Cassels argues, are fuelled strictly by corporate greed, while many of the flogged pharmaceuticals have little health benefit. Some may actually be hazardous. Of the latter, a number have been widely publicized, like the perils of taking estrogen for menopause. Furthermore, treatments for osteoporosis, prehypertension, prediabetes, social anxiety disorder, andropause and nail fungus are among those identified as little more than a sham, if not downright dangerous.

The medical profession, driven by the dictates of the pharmaceutical industry, contributes to a self-perpetuating cycle of affairs that Cassels calls "disease mongering," in which all involved profit from deluding people into believing there is a pharmaceutical solution to whatever may ail them.

In short, all pharmaceutical therapies invariably evolve into another staple of the monthly fee-for-service invoice and another few zeros at the end of the drug industry's annual profit charts. As for the poor beleaguered patient, well, caveat emptor, particularly with respect to the long-term effects of consuming a specific pharmaceutical, which are unknown because, of course, the drug had to be rushed to market and there was no strict requirement for follow-up studies. Moreover, if someone is sickened by an intervention, well, that ultimately adds up to another patient, requiring another pharmaceutical intervention, ad infinitum, ad nausem.

Indeed, there are times when these downright ditties are downright depressing. Behind their charm lie harsh truths about the hard evidence, or lack thereof, presented in the form of endnotes called "The Fine Print," miniessays on each of specific conditions, interventions or medical practices identified in the 26 poems.

It's tough not to conclude that this is bathroom reading, for manic depressives.

Yet, beneath the cynicism lies a vital message, the importance of inculcating a measure of healthy skepticism when advised by the medical and pharmaceutical industries to consume a drug.

There is, of course, a careful balance, as Cassels acknowledges in saying that many doctors are altogether wellintentioned and many pharmaceutical products are altogether efficacious, which is fortunate given most patient's implicit 